\title{
HUBUNGAN ANTARA KECERDASAN MATEMATIS-LOGIS DENGAN HASIL BELAJAR ILMU PENGETAAHUAN ALAM SISWA KELAS VI SDN SAWOTRATAP I GEDANGAN
}

\section{Amat Susanto}

(Pendidikan Guru Sekolah Dasar, Fakultas Keguruan dan Ilmu Pendidikan, Universitas PGRI Adi Buana Surabaya) susantoamat@gmail.com

\section{Nurmida Catherine Sitompul}

(Pendidikan Guru Sekolah Dasar, Fakultas Keguruan dan Ilmu Pendidikan, Universitas PGRI Adi Buana Surabaya) catherine sitompul@yahoo.com

\section{Triman Juniarso}

(Pendidikan Guru Sekolah Dasar, Fakultas Keguruan dan Ilmu Pendidikan, Universitas PGRI Adi Buana Surabaya) Trimanunipa@yahoo.com

\begin{abstract}
Abstrak
Penelitian ini adalah penelitian korelasional, yang bertujuan untuk mengetahui hubungan antara keceerdasan matematis-logis dengan hasil belajar IPA pada siswa kelas VI SDN Sawotratap I Gedangan. Populasi dalam penelitian ini adalah SDN Sawotratap I Gedangan. Sampel berasal dari seluruh siswa kelas VI yang berjumlah 169 siswa. Data penelitian ini dikumpulkan dengan menggunakan tes kecerdasan matematis-logis dan dokumentasi hasil belajar Ilmu Pengetahuan Alam. Tes kecerdasan matematis-logis terdiri dari 15 butir pertanyaan yang bersumber dari internet. Sedangkan dokumentasi hasil belajar Ilmu Pengetahuan Alam berasal dari nilai rata-rata 4 kali ulangan harian. Ulangan harian disusun dan dilaksanakan oleh guru yang bersangkutan. Hasil penelitian ini menunjukkan terdapat hubungan antara kecerdasan matematis-logis dengan hasil belajar IPA. Korelasi kecerdasan matematis-logis dengan hasil belajar IPA $\left(r_{x y}\right)$ sebesar 0,510 dengan kategori sedang.
\end{abstract}

Kata Kunci: Kecerdasan Matematis-Logis dan Hasil Belajar IPA. 


\section{Abstrack}

This study is a correlational study, which aims to determine the relationship between logical-mathematical intelligences with science learning outcomes in the sixth grade students of SDN Sawotratap I Gedangan. The population in this study is SDN Sawotratap I Gedangan. The samples come from the entire sixth grade students totaling 169 students.The data was collected by using a mathematical-logical intelligence tests and documentation of the Natural Sciences learning outcomes. Logical-mathematical intelligence test consists of 15 items derived from internet inquiries. While the documentation of the Natural Sciences learning outcomes derived from the average value of 4 times daily tests. Daily tests developed and implemented by the teacher concerned.The results of this study indicate there is a relationship between mathematicallogical intelligence with science learning outcomes. Logical-mathematical intelligence correlation with learning outcomes IPA (rxy) of 0,510 with moderate category.

Keywords: Logical-Mathematical Intelligence and Learning Outcomes

Kecerdasan majemuk ditemukan oleh Howard Gardner pada tahun 1983. Gardner adalah seorang codirector pada Project Zero, sebuah kelompok riset di Harvard Graduate School of Education. Dari proyek penelitian inilah Gardner menemukan kecerdasan majemuk (Multiple Intelligence). Pada awalnya, kecerdasan ini hanya terdiri atas tujuh jenis kecerdasan. Kemudian, penelitian dilanjutkan dan ditemukan dua jenis kecerdasan lagi, sehingga jumlahnya menjadi sembilan. Hasil temuan tersebut kemudian dipublikasikan dalam bentuk buku yang berjudul Frames of Mind: The Theory of Multiple Intelligence pada tahun 1983. Adapun kesembilan jenis kecerdasan yang dimaksud adalah kecerdasan linguistik, logikamatematika, visual, kinestetik, musikal, interpersonal, intrapersonal, naturalis dan eksistensial (Suyadi, 2009:151).

Kecerdasan matematis-logis sering disebut berpikir ilmiah, termasuk berpikir deduktif dan induktif. Kecerdasan ini merupakan kecerdasan otak linier yang bisa diaktifkan bila seseorang menghadapi masalah atau tantangan baru dan berusaha menyelesaikannya. Kecerdasan ini berfungsi untuk mengontrol rasionalisme matematis (penjumlahan, pengurangan, perkalian dan pembagian). Kecerdasan matematis-logis memungkinkan seseorang terampil dalam melakukan hitungan, penghitungan atau kuantifikasi, mengemukakan proposisi dan hipotesis dan melakukan operasi matematis. Kecerdasan ini selalu menghitung dan memperkirakan setiap kondisi, keadaan, dan lingkungan agar bisa berguna dan bermanfaat bagi kemajuan dan kesuksesan. Armstrong (2013:6).

Kecerdasan matematis-logis adalah kemampuan menggunakan angka secara efektif (misalnya sebagai ahli matematika, akuntan pajak atau ahli statistik) dan untuk alasan yang baik (misalnya, sebagai ilmuan, pemrogram komputer, atau ahli logika). Kecerdasan ini meliputi kepekaan terhadap pola-pola dan hubungan-hubungan yang logis, 
pernyataan dan dalil (jika-maka, sebabakibat), fungsi, dan abstraks terkait lainya (Amstrong, 2013:6). Dengan demikian kecerdasan matematis-logis berkaitan dengan nalar dan matematika. Ilmu Pengetahuan Alam (IPA) didefinisikan sebagai kumpulan pengetahuan yang tersusun secara terbimbing. Bahwa IPA berhubungan dengan cara mencari tahu tentang alam secara sistematis, sehingga bukan hanya penguasaan kumpulan pengetahuan yang berupa fakta, konsep atau prinsip saja tetapi juga merupakan suatu proses penemuan-penemuan.

Kecerdasan matematis-logis yang berkaitan dengan nalar, angka dan kemampuan ilmiah yang sangat berhubungan dengan pembelajaran IPA, karena pada pembelajaran IPA terdapat berbagai macam aspek yang mencakup kemampuan ilmiah, nalar dan angka. Misalnya, pada pembelajaran Fisika yang merupakan cabang dari pembelajaran Ilmu Pengetahuan Alam, membutuhkan kemampuan mengolah angka dengan baik. Sedangkan pada pelajaran biologi, membutuhkan kemampuan ilmiah yang baik.

Kecerdasan matematis-logis meru-pakan kemampuan menggurutkan, menyukai angka, logika dan keteraturan, kemampuan dalam menyelesaikan masalah, mengerti pola hubungan dan mampu berpikir deduktif dan induktif. Sedangkan dalam mata pelajaran IPA merupakan ilmu yang mempelajari tentang alam sekitar, bersikap ilmiah, menyelasaikan masalah secara ilmiah untuk menghasilkan produk-produk IPA yaitu fakta, konsep generalisasi, hukum dan teori-teori baru sehingga kecerdasan matematis-logis yang dimiliki siswa diharapkan mampu membantu siswa dalam mencapai hasil belajar yang memuaskan.

Melihat paparan diatas, penelitian ini ingin menjawab permasalahan, adakah hubungan antara kecerdasan matematis-logis dengan hasil belajar IPA pada siswa kelas VI SDN Sawotratap I Gedangan? Yang hasilnya diharapkan dapat memberikan bahan informasi bagi penelitian selanjutnya dan memberikan alternatif bagi guru agar dalam menentukan metode yang tepat dalam pembelajaran memasukkan aspek kecerdasan matematis-logis siswa dalam perancangan pembalajaran IPA.

\section{METODE PENELITIAN}

Penelitian ini merupakan penelitian korelasional yang bertujuan untuk mengetahui hubungan antara kecerdasan matematis-logis dengan hasil belajar IPA pada siswa kelas VI SDN Sawotratap I Gedangan. Sampel berasal dari seluruh siswa kelas VI yang berjumlah 169 dan berasal dari lima kelas. Sedangkan pengumpulan data penelitian dilakukan dengan cara membagikan tes kecerdasan matematislogis.

Tes Kecerdasan matematis logis berjumlah 15 pernyataaan. Sedangkan hasil belajar IPA diperoleh dari dokumentasi nilai rata-rata yang diambil dari nilai ulangan harian 4 pokok bahasan yang dilakukan oleh guru. Dalam penelitian ini, teknik analisis yang digunakan adalah teknik korelasi product 
moment dan penghitungannya di bantu program SPSS Versi 20.

\section{HASIL PENELITIAN}

Untuk mengetahui hubungan antara kecerdasan matematis-logis dengan hasil belajar IPA, peneliti membagikan tes kecerdasan matematislogis pada siswa kemudian mendokumentasikan nilai hasil belajar IPA yang berasal dari nilai rata-rata dari empat kali nilai ulangan harian yang dilakukan oleh guru. Dari kedua data tersebut peneliti menghitung korelasi antara kecerdasan matematis logis dengan hasil belajar masing-masing siswa yang dalam penghitungannya menggunakan bantuan program SPSS Versi 20. Hasil penghitungan tersebut adalah sebagai berikut.

Tabel 1 Korelasi Kecerdasan MatematisLogis dengan Hasil Belajar IPA

\section{Correlations}

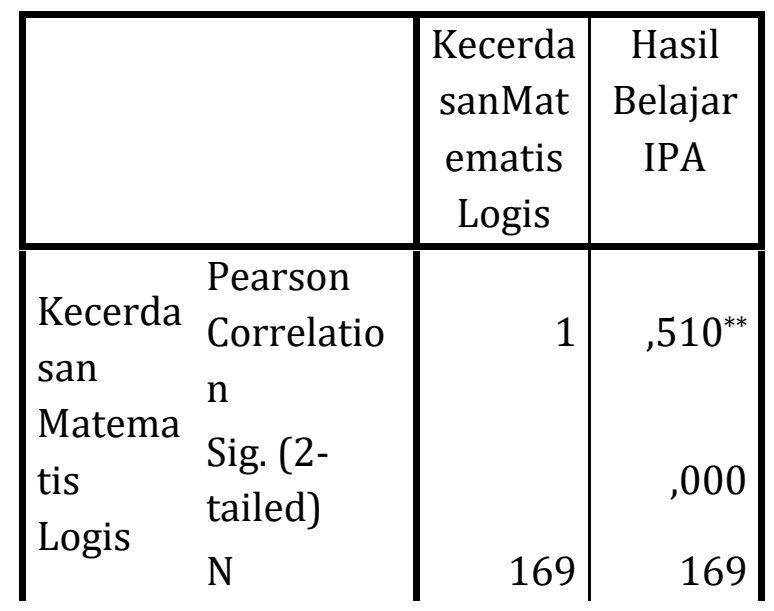

\begin{tabular}{|ll|r|r|} 
& $\begin{array}{l}\text { Pearson } \\
\text { Hasil }\end{array}$ & Correlatio \\
Belajar & n & $510^{* *}$ & 1 \\
IPA & $\begin{array}{l}\text { Sig. (2- } \\
\text { tailed) } \\
\mathrm{N}\end{array}$ &, 000 & \\
& $\mathrm{~N}$ & 169 & 169 \\
\hline
\end{tabular}

Berdasarkan hasil perhitungan korelasi dengan bantuan SPSS Versi 20, diperoleh $r_{x y}=0,510$. Sedangkan nilai $r$ tabel dengan taraf siginifikan $5 \%$ bernilai 0,148 . Dengan demikian, maka nilai $r$ hitung > $r$ tabel. Maka, ada hubungan antara kecerdasan matematis-logis dengan hasil belajar IPA dengan kategori sedang.

Berdasarkan hasil penelitian yang telah dilakukan, Hipotesis Alternatif (Ha) yang berbunyi ada hubungan antara kecerdasan matematis-logis dengan hasil belajar IPA siswa kelas VI SDN Sawotratap I Gedangan diterima.

\section{PEMBAHASAN}

Penelitian hubungan antara kecerdasan matematis-logis dengan hasil belajar IPA siswa kelas VI SDN Sawotratap I Gedangan dengan menggunakan teknik korelasi menghasilkan temuan penelitian yaitu terdapat hubungan antara kecerdasan matematis-logis dengan hasil belajar IPA pada siswa kelas VI SDN Sawotratap I Gedangan.

Berdasarkan data hasil penelitian diketahui jumlah subjek sebagai sampel yang dianalisis adalah 169 siswa kelas VI SDN Sawotratap I Gedangan. Data kecerdasan matematis-logis diperoleh dari tes kecerdasan matematis-logis, sedangkan data hasil belajar diperoleh 
dari nilai rata-rata yang berasal dari empat kali nilai ulangan harian yang dilakukan oleh guru. Kedua data tersebut dianalisis dengan menggunakan korelasi product moment yang penghitungannya menggunakan bantuan program SPSS Versi 20.

Korelasi antara kecerdasan matematis-logis dengan hasil belajar IPA bernilai 0,510 dengan kategori sedang. Hal ini menunjukkan bahwa hipotesis nihil (Ho) ditolak, sedangkan hipotesis alternatif $(\mathrm{Ha})$ diterima. Dengan kata lain, kecerdasan matematis-logis berhubungan dengan hasil belajar IPA. Hubungan tersebut dalam katagori sedang karena pada proses pembelajaran IPA di Sekolah Dasar mencakup beberapa aspek yang lebih menonjolkan materi dasar. Di Sekolah Dasar, pembelajaran IPA cenderung dilakukan dengan ceramah bukan analisis ilmiah dan mengolah angka seperti pada pelajaran Biologi dan Fisika pada tingkat SMP. Guru SD dapat memberikan stimulan-stimulan untuk kecerdasan matematis-logis agar pada tingkat lanjut, keceerdasan matematislogis siswa dapat meningkat dan di harapkan hasil pembelajaran IPA pada tingkat lanjut juga akan meningkat.

\section{SIMPULAN}

Berdasarkan hasil penelitian maka dapat diambil kesimpulan bahwa terdapat hubungan positif antara kecerdasan matematis-logis dengan hasil belajar Ilmu Pengetahuan Alam siswa kelas VI di SDN Sawotratap 1 Gedangan Sidoarjo. Hubungan tersebut memiliki tingkat korelasi dengan katagori sedang $(r x y=510)$.

\section{SARAN}

Berdasarkan hasil penelitian dengan kesimpulan yang telah dipaparkan di atas, maka peneliti memberikan saran-saran sebagai berikut

1. Penelitian ini dapat dipertimbangkan oleh guru dalam pembelajaran Ilmu Pengetahuan Alam khususnya pada materi yang berkaitan dengan alam supaya dilakukan dengan memperbanyak praktek IPA. Hal ini dilakukan agar kecerdasan matematis-logis yang dimiliki siswa dapat berkembang dengan baik dan optimal sehingga hasil belajar yang didapat juga akan maksimal.

2. Bagi siswa, diharapkan dapat mengikuti kegiatan pembelajaran dengan baik sehingga tujuan pembelajaran dapat tercapai.

3. Perlu diadakan penelitian lanjutan. Penelitian dilakasanakan di SDN Sawotratap I Gedangan menggunakan sampel yang homogen yaitu siswa yang memiliki status ekonomi dan lingkungan sosial yang sama, untuk memperoleh generalisasi yang lebih baik, maka disarankan kepada peneliti-peneliti lain untuk mengadakan refleksi dengan memakai populasi dan sampel yang berbeda dengan jumlah yang lebih banyak (beberapa sekolah). 


\section{DAFTAR PUSTAKA}

Ahmad, Mirza Bahirudin. 2012. Teori Kecerdasan Ganda Multiple Intelligence dan Penerapannya. http://mynamemirza.wordpress. com/2012/06/09/teori-

kecerdasan-ganda-multipleintelligence-danpenerapannya.com diunduh, 21 agustus 2013.

Armstrong, Thomas. 2013. Kecerdasan Multipel di Dalam Kelas Jakarta: Indeks.

B, Hamzah. dan Umar, MK. 2009. Mengelola Kecerdasan Dalam Pembelajaran. Jakarta: PT. Bumi Aksara.

http://ayahalby.wordpress.com/2011/0 2/22 /hakikat-ipa-di-sd/feed/ diakses pada tanggal 28 Agustus 2013.

Ramdani, Dede. 2012. Proses Pembelajaran Ipa di SD http://dederamdanipgsdipab.co $\mathrm{m} / 2012 / 12 /$ proses-

pembelajaran-ipa-di-sd-menurutRutherford dan Ahlgren 1990.html diunduh, 28 agustus 2013.

Yaumi, Muhammad. 2012. Pembelajaran Berbasis Multiple Intelligences Jakarta: Dian Rakyat 